\title{
Effect of Surface Roughness on Elastohydrodynamic Lubrication Performance of Cylindrical Roller Bearing
}

\author{
Xia YANG, Yachao LI, Guangming LIU, Jianmei WANG
}

\begin{abstract}
In order to study the effect of surface roughness on the Elastohydrodynamic Lubrication (EHL) performance of cylindrical roller bearing, an EHL model of cylindrical roller bearing with three dimensional surface cosine roughness based on finite length line contact theory is established. The EHL performance of cylindrical roller bearing is calculated by the Finite Difference Method (FDM) program, with which the effects of surface cosine roughness amplitude, wavelength and texture angle on EHL performance of cylindrical roller bearing are analyzed. The numerical results show that the roughness amplitude, wavelength and texture angle have great influence on the EHL performance in the contact area. The increase of roughness amplitude and wavelength in a reasonable range is beneficial to the enhancement of EHL performance of the cylindrical roller bearing, and the transverse roughness is more favorable to enhance the bearing capacity and reduce the friction coefficient.
\end{abstract}

Keywords: cylindrical roller bearing; Elastohydrodynamic Lubrication (EHL); Finite Difference Method (FDM); three dimensional cosine roughness

\section{INTRODUCTION}

Four-row cylindrical roller bearings, which can bear large radial loads, are widely used in rolling mill. Their precision, life, vibration and reliability play a decisive role in the normal operation of rolling mill and the quality of rolled products. Heavy loads are operated on the four-row cylindrical roller bearings, whose lubricating performances have a great influence on the bearing's life, vibration and other properties. Therefore, it is of great significance to study the elastohydrodynamic lubrication (EHL) theory of four-row cylindrical roller bearings. The EHL of cylindrical roller bearings belongs to the category of finite length roller line contact EHL. For many years, the research on the EHL characteristics of finite roller line contact was one of the hot topics.

In 1949, literature [1] combined Hertz contact theory with Reynolds lubrication theory, and gave the first analytical solution of linear contact EHL. After that, the linear contact elastohydrodynamic theory entered a rapid development period [2-3]. Literature [4] analyzed the elastohydrodynamic of the straight generatrix roller modified by tangent and intersecting circular arc at the end of the roller by inverse solution, and obtained the influence of suction velocity and the modification quantity of the busbar on the oil film pressure and thickness. Literature [5] obtained the elastohydrodynamic numerical solution of isothermal finite length straight busbar roller, revealed the edge effect of roller lubrication, and obtained the conclusion that the minimum film thickness is located at the end of roller.

Since the $21^{\text {st }}$ century, with the rapid development of computer technology, the study of finite length line contact elastohydrodynamic theory has entered a period of rapid development [6]. Literature [7] took into account the thermal effect on the basis of isothermal solution, and obtained the complete numerical solution of thermoelastohydrodynamic lubrication (THL) with finite length contact. Literature [8] studied the edge effect in finite length contact thermo-elastohydrodynamic lubrication (THL), and compared the lubrication characteristics of different modified rollers. Literature [9] studied the problem of THL with finite length contact at different secondary temperatures and oil supply temperatures.

There is no absolutely smooth surface in engineering, and it is necessary to study the effects of surface roughness, because of the same magnitudes of oil film thickness and the metal surface roughness formed by cutting. It is also one of the topics, which the scholars from all over the world are interested in. Literature [10] discussed the influence of surface roughness on soft EHL, and pointed out that the pressure peak produced by roughness would not flatten the rough plane. Literature [11] studied the effect of plastic deformation of surface roughness on linear contact EHL. Literature [12] studied the EHL of isothermal finite length line contact with surface roughness, and analyzed the effects of roller contact length, crown and end chamfer on the oil film thickness and stress concentration. Literature [13] studied the EHL characteristics of isothermal finite length line contact with surface roughness. Literature [14] proposed an analytical method for THL of cylindrical roller bearings with the effect of thermoelastic deformation and roughness. Literature [15] proposed an analytical model to investigate the hydrodynamic lubrication of the short groove, and analyzed the influence of geometrical parameters of the short grooves on the hydrodynamic lubrication. Literature [16] developed a mixed EHL model and studied the effects of the wavelength and amplitude of roughness, working conditions on the roughness orientations. Literature [17] revealed the connection between the film thickness and the friction for a uniform surface texture on transition from full film to mixed lubrication in non-conformal contacts. Literature [18] studied a finite length roller subjected to a time varying load using a full-system finite element approach, and got the behaviour of finite line EHL contacts under transient conditions. Literature [19] proposed a numerical method for analyzing point contact thermal elastohydrodynamic lubrication of angular contact ball bearing based on the point contact thermal elastohydrodynamic lubrication theory.

To sum up, few literatures have systematically analyzed the influence of several factors of roughness on EHL characteristics of the cylindrical roller bearing. In this paper, Newtonian fluid lubrication model will be used to 
study the EHL performance of cylindrical roller bearings in line contact. By changing the amplitude, wavelength and texture angle of surface roughness, the influence of roughness on EHL characteristics of cylindrical roller bearings will be analyzed

\section{FINITE LENGTH LINE CONTACT THEORY 2.1 Mathematical Model}

Finite length line contact pair is composed of two end modification roller $\mathrm{A}$ and roller $\mathrm{B}$, as shown in Fig. 5. where, $R_{x}$ and $R_{y}$ represent the radius and the repair radius of the rollers, $L$ and $l$ represent the length and the line segment length of roller [20].

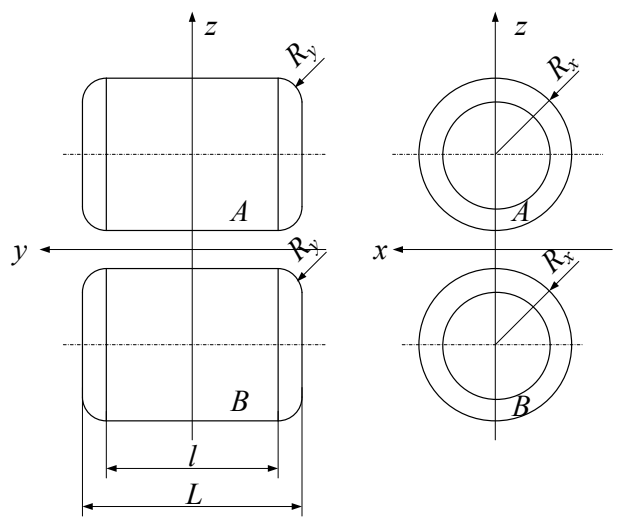

Figure 1 Sketchmap of finite line contact pair

\subsection{Basic Equation}

(1) Reynolds equation of finite length line contacts is expressed as follows:

$\frac{\partial}{\partial x}\left(\frac{\rho h^{3}}{\eta} \frac{\partial p}{\partial x}\right)+\frac{\partial}{\partial y}\left(\frac{\rho h^{3}}{\eta} \frac{\partial p}{\partial y}\right)=12 u_{s} \frac{\partial(\rho h)}{\partial x}$,

where, $p$ represents the oil film pressure, $h$ represents the film thickness, $\rho$ represents the oil density, $\eta$ represents the oil viscosity, $u_{s}$ represents the suction velocity.

(2) Boundary conditions equations are expressed as follows:

$\left\{\begin{array}{l}p\left(x_{\text {in }}, y\right)=p\left(x_{\text {out }}, y\right)=p\left(x, y_{\text {in }}\right)=p\left(x, y_{\text {out }}\right) \\ p(x, y) \geq 0\left(x_{\text {in }}<x<x_{\text {out }}, y_{\text {in }}<y<y_{\text {out }}\right)\end{array}\right.$

where, $x_{\text {in }}$ and $x_{\text {out }}$ represent the entrance and export coordinate of $x$ direction respectively, $y_{\text {in }}$ and $y_{\text {out }}$ represent the entrance and export coordinate of $y$ direction.

(3) Film thickness equation is expressed as follows:

$h(x, y)=h_{0}+\frac{x^{2}}{2 R}+v(x, y)-s(x, y)$,

where, $h_{0}$ represents the rigid film thickness, $R=$ $R_{1} R_{2} /\left(R_{1} \pm R_{2}\right)$ represents the equivalent radius of curvature, when the centers of curvature of two contact surfaces are located on different sides of the contact point, take the symbol of '-', else take the symbol of ' + ', $v$ represents the elastic deformation, $s$ represents the roughness.

(4) Elastic deformation equation is expressed as follows:

$$
v(x, y)=\frac{2}{\pi E^{\prime}} \iint_{\Omega} \frac{p(\xi, \zeta)}{\sqrt{(x-\xi)^{2}+(y-\zeta)^{2}}} \mathrm{~d} \xi \mathrm{d} \zeta
$$

where, $E^{\prime}=\frac{1}{2}\left(\frac{1-\mu_{1}^{2}}{E_{1}}+\frac{1-\mu_{2}^{2}}{E_{2}}\right)$ represents the compositive elasticity modulus, $E_{1}$ and $E_{2}$ represent the elasticity moduluses of the two contact bodies respectively, $\mu_{1}$ and $\mu_{2}$ represent the Poisson ratios of the two contact bodies respectively.

(5) Roughness equation is expressed as follows:

$s(x, y)=R a \cdot \cos \left(\frac{2 \pi \cos \beta}{l} x\right) \cos \left(\frac{2 \pi \sin \beta}{l} y\right)$

where, $R a$ represents the roughness peak amplitude, $l$ represents the roughness wavelength, $\beta$ represents the roughness texture direction.

(6) Viscous pressure equation is expressed as follows:

$\eta=\eta_{0} \exp \left\{\left(\ln \eta_{0}+9.67\right)\left[-1+\left(1+p_{0} p\right)^{z}\right]\right\}$

where, $z=\alpha /\left[5.1 \times 10^{-9}\left(\ln \eta_{0}+9.67\right)\right]$, usually take 0.68 , $\eta_{0}$ represents the initial oil viscosity, $p_{0}$ represents the pressure coefficient, usually take $5.1 \times 10^{-9}$.

(7) Dense pressure equation is expressed as follows:

$\rho=\rho_{0}\left(1+\frac{0.6 \times 10^{-9} p}{1+1.7 \times 10^{-9} p}\right)$

where, $\rho_{0}$ represents the initial oil density.

(8) Load equation is expressed as follows:

$\iint_{\Omega} p(x, y) \mathrm{d} x \mathrm{~d} y=w$

where $w$ represents the external applied load.

(9) Friction coefficient equation

Friction coefficient is an important parameter in the study of EHL. Under the condition of steady state and sufficient oil supply, friction coefficient is determined by the shear performance of lubricant.

In the research of bearing EHL theory, the lubrication oil is generally regarded as Newtonian fluid. In the analysis of point contact and line contact elastomeric flow, the oil film thickness and pressure obtained are consistent with the actual situation. However, in the process of solving the friction, it is found that the friction calculated by using Newtonian fluid deviates greatly from the reality. In addition, it turns out that in the simple fluid that we use, the rheological properties of lubrication oil can be accurately described by Ree-Eyring model. Therefore, the Ree-Eyring 
non-Newtonian fluid is used to calculate the friction in the contact area of cylindrical roller bearing, and to obtain the friction coefficients.

Constitutive equation of Ree-Eyring Model is expressed as follows [14]:

$$
\left\{\begin{array}{l}
\tau_{x}=\tau_{0} \sinh ^{-1}\left(\frac{\eta}{\tau_{0}} \frac{\partial u}{\partial z}\right) \approx \tau_{0} \sinh ^{-1}\left(\frac{\eta u}{\tau_{0} h_{\mathrm{a}}}\right) \\
\tau_{y}=\tau_{0} \sinh ^{-1}\left(\frac{\eta}{\tau_{0}} \frac{\partial v}{\partial z}\right) \approx \tau_{0} \sinh ^{-1}\left(\frac{\eta v}{\tau_{0} h_{\mathrm{a}}}\right)
\end{array}\right.
$$

where, $\tau_{0}$ represents the extreme shear force of lubrication oil, $h_{\mathrm{a}}$ represents the average oil film thickness of the contact area of the rolling bullet flow, $u$ and $v$ represent suction velocity of roll direction and end-flow rate of the lubrication oil respectively.

Therefore, the calculation formula of friction coefficient can be derived as follows:

$$
\mu=\frac{1}{w} \sqrt{\left(\iint_{\Omega} \tau_{x} \mathrm{~d} x \mathrm{~d} y\right)^{2}+\left(\iint_{\Omega} \tau_{y} \mathrm{~d} x \mathrm{~d} y\right)^{2}}
$$

\section{FINITE DIFFERENCE METHOD (FDM)}

To facilitate numerical calculation, the above basic Eqs. (1)-(10) are transformed into dimensionless form. Dimensionless quantities are defined as: $P$ represents the dimensionless oil film pressure, $P=p / p_{H} ; H$ represents the dimensionless oil film thickness, $H=h / h_{0}, h_{0}$ represents film thickness parameter, $h_{0}=b^{2} / R ; \eta^{*}$ represents the dimensionless oil film viscosity, $\eta^{*}=\eta / \eta_{0} ; \rho^{*}$ represents the dimensionless oil film density, $\rho^{*}=\rho / \rho_{0} ; W$ represents the dimensionless load, $W=w /\left(E^{\prime} R\right) ; X$ represents the dimensionless coordinate variables of rolling direction, $X$ $=x / b ; Y$ represents the dimensionless coordinate variables of busbar direction, $Y=y / b ; U$ represents the dimensionless velocity parameter, $U=\eta_{0} u_{s} /\left(E^{\prime} R\right)$.

The dimensionless Reynolds equation, oil film thickness equation, dense pressure equation, viscous pressure equation and load equation are discretized by FDM. In this paper, $X_{\text {in }}=2.5$ and $X_{\text {out }}=1.5$, the EHL region is divided equidistantly. Through the continuous iterations of oil film thickness and pressure in steady state, the new oil film thickness and pressure are calculated as initial values, until the iterative process can satisfy the precision requirement of convergence. In order to improve the convergence accuracy and ensure the reliability of the numerical solution, the convergent accuracy of pressure and load is taken as $10^{-5}$. Fig. 2 shows the flowchart of FDM calculation program. It can be briefly summarized as follows:

(1) Input basic parameters of the bearing and the load $w$, then calculate contact width $b$ according to the load $w$.

(2) Set the initial oil film thickness $h_{0}$ and oil film pressure $p_{0}$.

(3) Set surface roughness amplitude, wavelength and texture angle.

(4) Calculate the viscosity, density, elastic deformation and oil film thickness.
(5) Solve the Reynolds equation by using the FDM, and obtain the new oil film thickness $h$ and oil film pressure $p$.

(6) Judge if the convergence precision of pressure is satisfied or not. If yes, go to step (7). Otherwise, go to step (4).

(7) Judge if the convergence precision of pressure is satisfied or not. If yes, go to step (8). Otherwise, go to step (4).

(8) Calculate the dimensional oil film thickness, oil filmpressure and friction coefficients, and output the results.

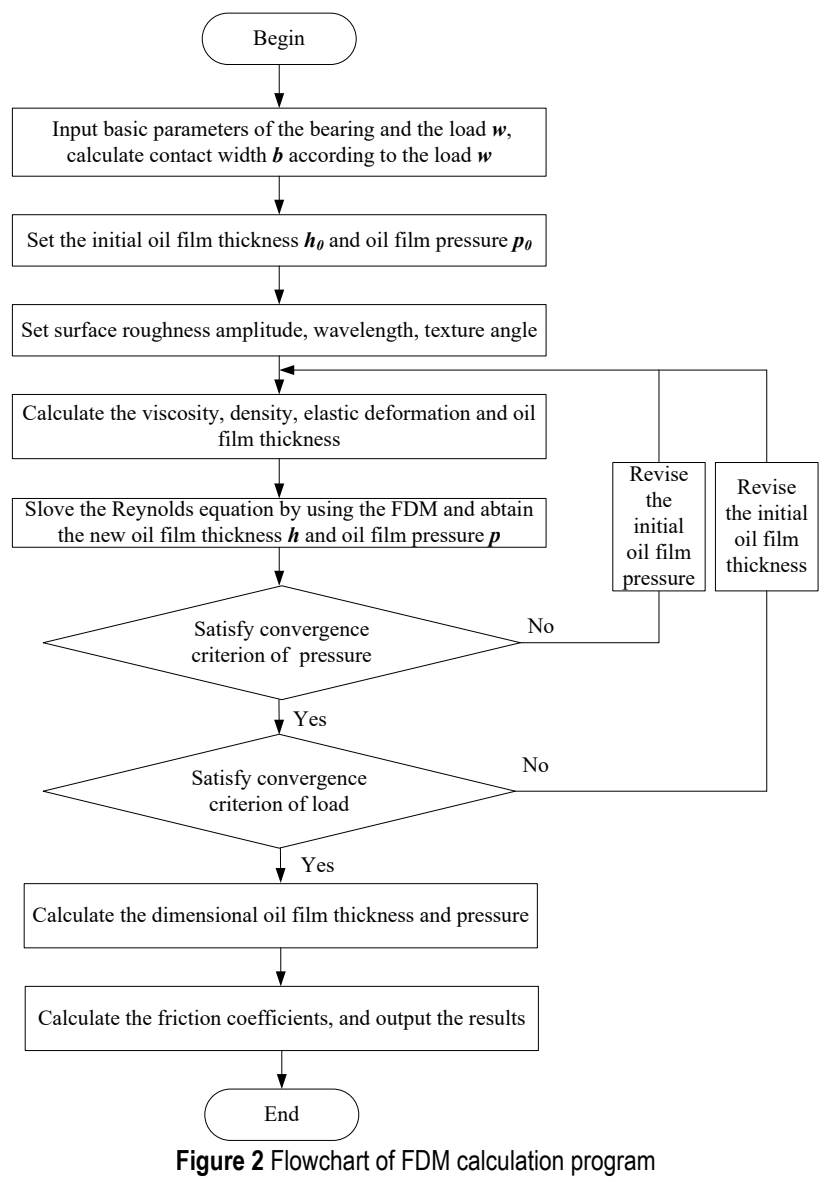

\section{EXAMPLES AND RESULT ANALYSIS}

In this paper, the research object is a four-row cylindrical roller bearing, whose bearing type is FC2234120. One row of the bearing is taken as the EHL research object. The calculation parameters are shown in Tab. 1.

Table 1 Basic calculation parameters

\begin{tabular}{|l|c|}
\hline \multicolumn{1}{|c|}{ Parameter } & Value \\
\hline Inner diameter of inner race & $110 \mathrm{~mm}$ \\
\hline Outer diameter of inner race & $124 \mathrm{~mm}$ \\
\hline Outer diameter of outer race & $170 \mathrm{~mm}$ \\
\hline Inner diameter of outer race & $154 \mathrm{~mm}$ \\
\hline Roller diameter & $30 \mathrm{~mm}$ \\
\hline Viscosity & $0.08 \mathrm{~Pa} \cdot \mathrm{s}$ \\
\hline Density & $875 \mathrm{~kg} / \mathrm{m}^{3}$ \\
\hline Elasticity modulus & $2.2 \times 10^{5} \mathrm{MPa}$ \\
\hline Poisson ratio & 0.3 \\
\hline External applied load & $10000 \mathrm{~N}$ \\
\hline
\end{tabular}




\subsection{Calculation Results under Smooth Condition}

Assuming that the contact surfaces between the roller and the races are smooth, after applying the external load as shown in Tab. 1, the oil film thickness and pressure in the EHL region between the roller and the inner race of the cylindrical roller bearing are obtained by the FDM calculation program. And the three dimensional cloud diagram and contour diagram of oil film thickness are shown in Fig. 3.

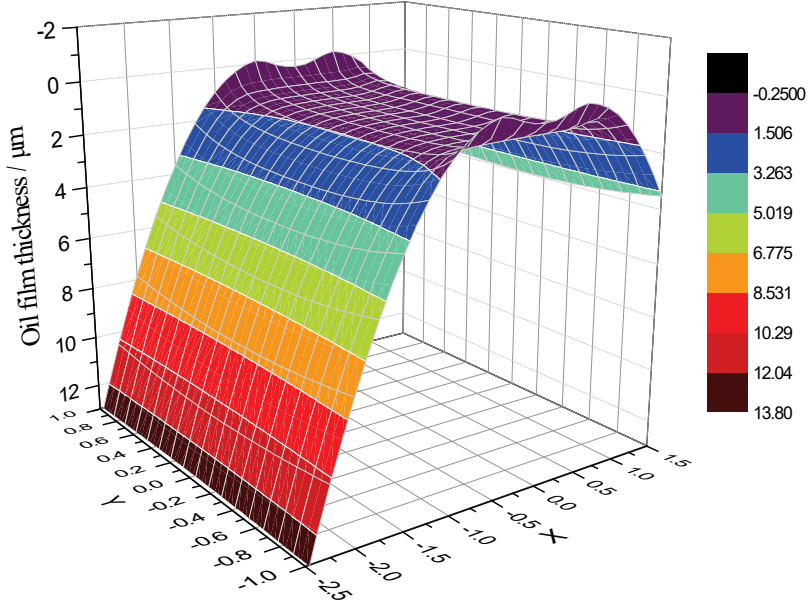

(a) Three dimensional cloud diagram

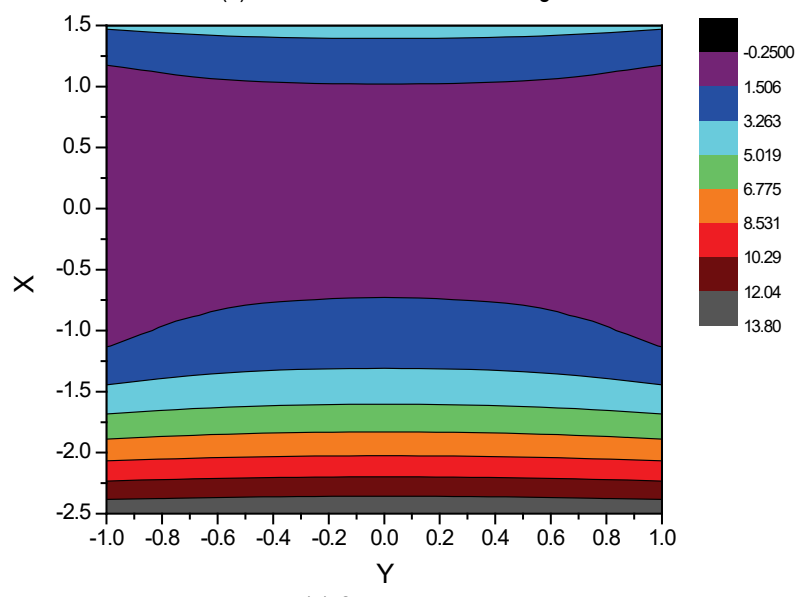

(b) Contour diagram

Figure 3 The oil film thickness

It can be seen from Fig. 3 that the oil film thickness presents a downward parabola distribution from the inlet region to the outlet region, and a wave trough of oil film appears in the outlet region. The oil film thickness in the range of Hertz contact width is about $1.5 \mu \mathrm{m}$. The oil film thickness distributes evenly along the busbar between roller and inner race. However, the oil film thickness decreases obviously in the end of roller, and the lubrication condition in the middle area deteriorates.

The three dimensional cloud diagram and contour diagram of oil film pressure are shown in Fig. 8. It can be seen from Fig. 8 that the oil film pressure presents a convex parabola distribution from the inlet region to the outlet region, and the secondary pressure peak appears in the outlet region. In the contact region of the roller busbar, the oil film pressure distributes evenly except the end regions, and the maximum pressure appears at the end of the roller and the inner race. Corresponding to the oil film thickness distribution in Fig. 3 and Fig. 4 shows that the lubrication condition is worse than that in the middle region, and the dangerous phenomenon of stress concentration appears at both ends.

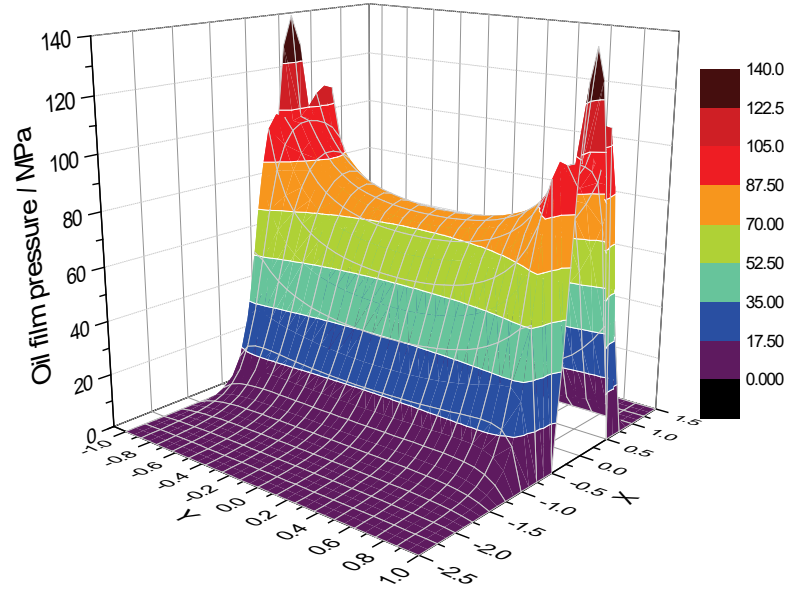

(a) Three dimensional cloud diagram

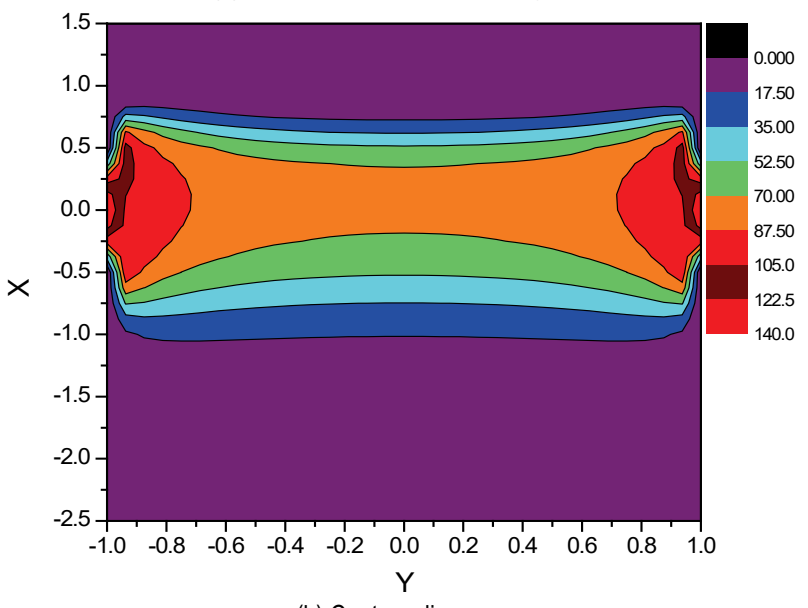

(b) Contour diagram

Figure 4 The oil film pressure

The three dimensional cloud diagram of friction coefficient is shown in Fig. 5(a), and when $Y=0$ and $X=$ 0 , the friction coefficients are shown in Fig. 5(b) and Fig. 5(c). It can be seen from Fig. 5(a) that the friction coefficient is larger in the inlet region than other region. The minimum friction coefficient appears at $X=0.5$ where near the outlet region from Fig. 9(b), and the value is $2.901 \times 10^{-3}$. From Fig. 5 (c), we know that along the busbar direction, the friction coefficients are approximate symmetric distribution relative to $Y=0$, and distribute uniformly in the middle region.

\subsection{The Effect of Surface Roughness Amplitude $R_{\mathrm{a}}$}

Now, let's analyze the effect of the surface roughness amplitude of the contact pair between the roller and the inner race. When the wavelength is $0.2 b$ ( $b$ is the contact width) and the texture angle is $60^{\circ}$, the calculation was carried out with different surface roughness amplitudes of $R a=0.02 h_{0}, 0.05 h_{0}$ and $0.1 h_{0}$. Fig. 6 and Fig. 8 show the three-dimensional distribution oil film thickness and pressure with different surface roughness amplitudes, receptively. When $Y=0$ and $X=0$, the two-dimensional oil film thickness, pressure and the friction coefficient are 
shown in Fig. 7, Fig. 9 and Fig. 10, respectively. From the calculation results we know that the value of surface roughness amplitude has great influence on the EHL characteristics of cylindrical roller bearings.

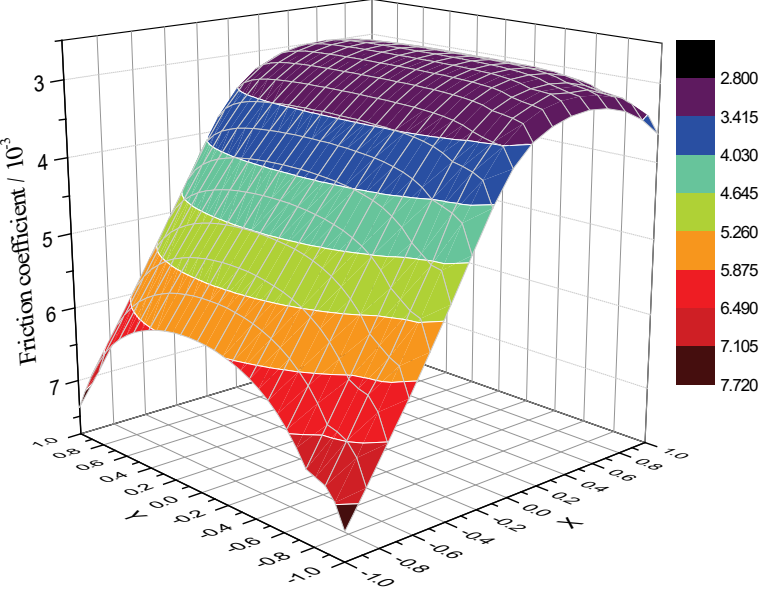

(a) Three dimensional cloud diagram

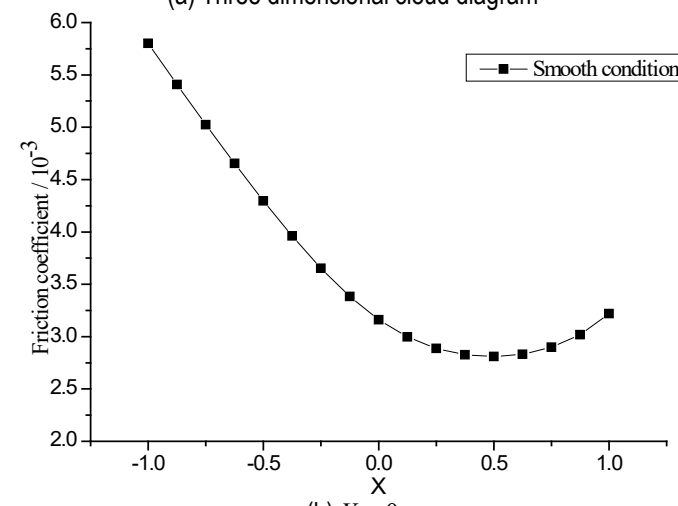

(b) $Y=0$

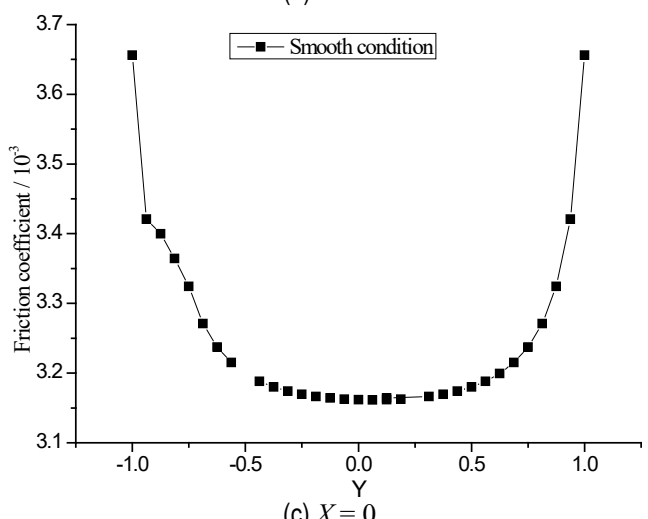

Figure 5 The friction coefficient

It can been seen from Fig. 6 and Fig. 7, that with the increase of the surface roughness amplitude, the peak and valley values of the oil film thickness both increase along the suction direction and the busbar direction. In the busbar direction, the minimum oil film thickness increases slightly at the ends of the roller, and the end lubrication situation is improved.

It can be seen from Fig. 8 that with the increase of the surface roughness amplitude, the oil film pressure increases continuously and fluctuates sharply. Fig. 9(a) shows the variation of oil film pressure along the suction direction. Fig. 9(b) shows the distribution of oil film pressure in the busbar direction, the oil film pressure fluctuates violently at the ends of the roller. At the same time, pressure peak and valley appear in the middle region of the busbar.

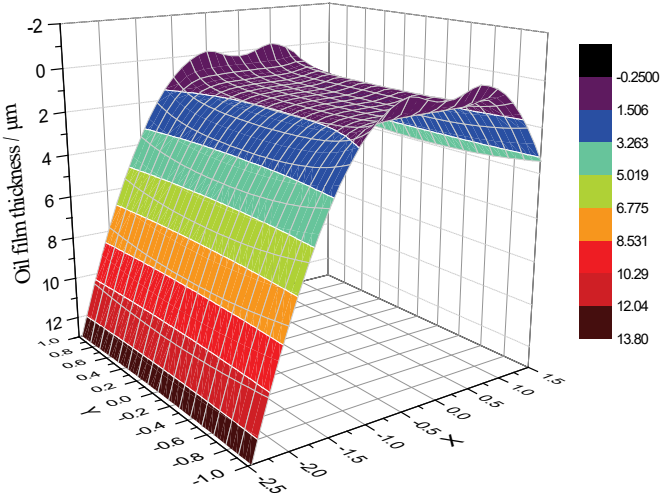

(a) $R a=0$

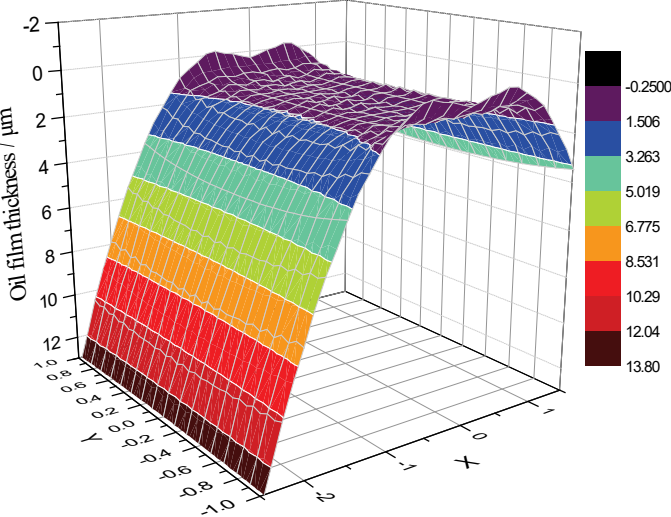

(b) $R a=0.02 h_{0}$

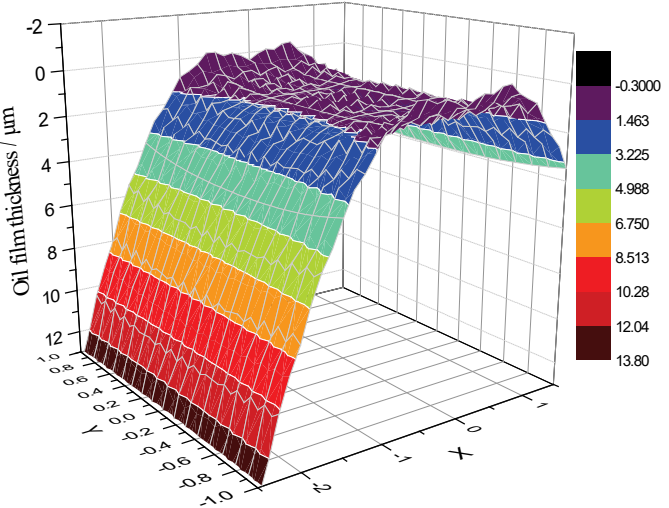

(c) $R a=0.05 h_{0}$

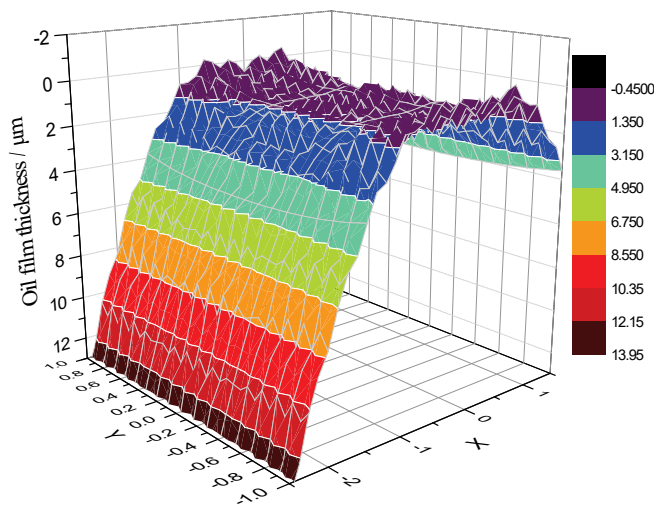

(d) $R a=0.1 h_{0}$

Figure 6 The three-dimensional distribution oil film thickness 


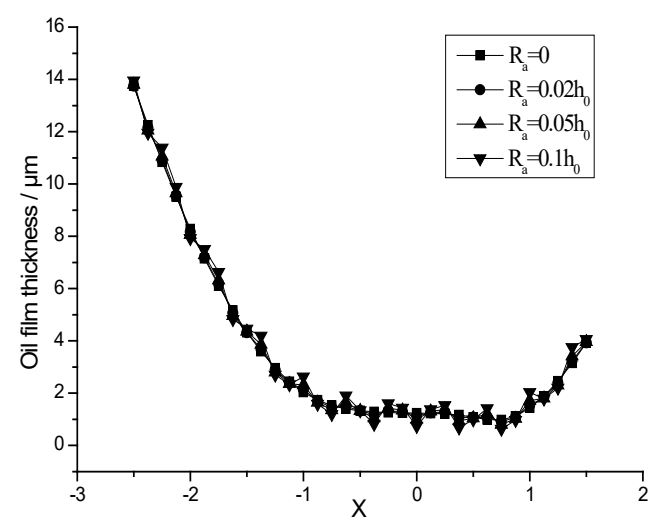

(a) $Y=0$

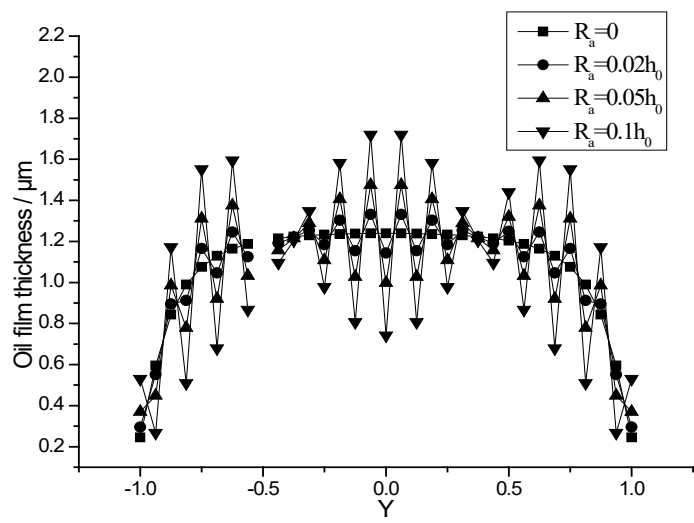

(b) $X=0$

Figure 7 The two-dimensional oil film thickness

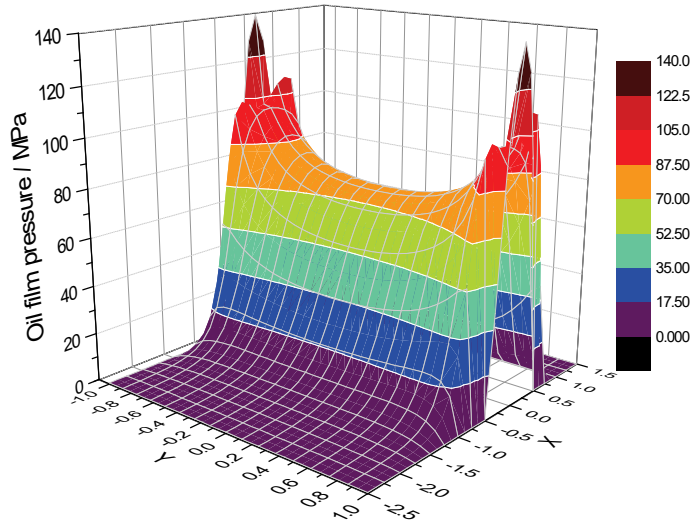

(a) $R a=0$

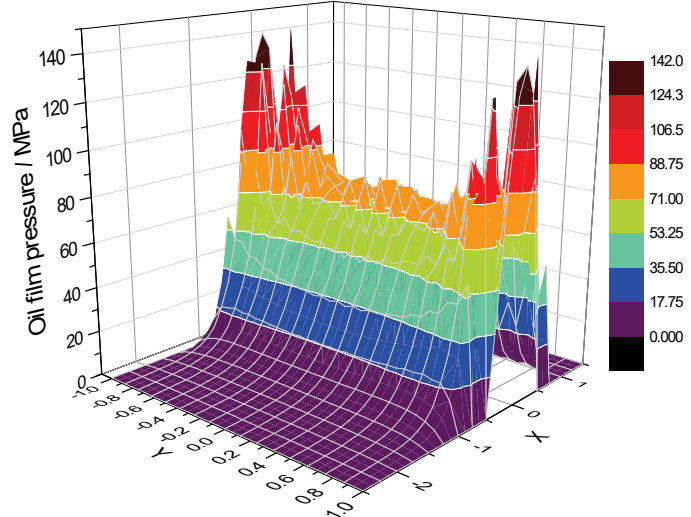

(c) $R a=0.05 h_{0}$

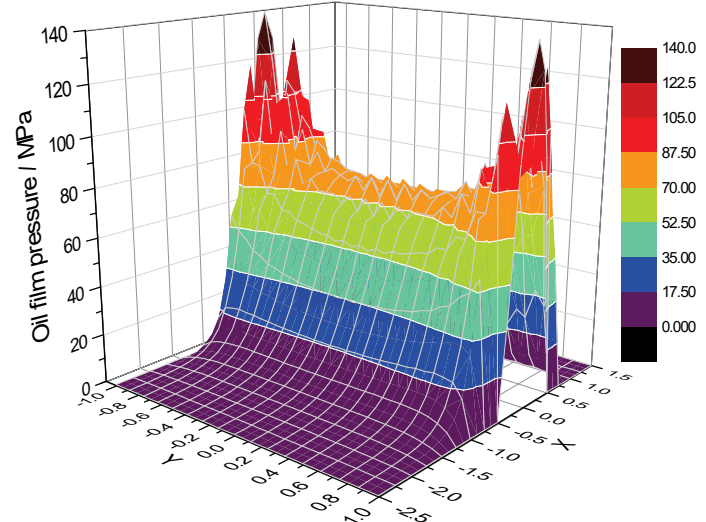

(b) $R a=0.02 h_{0}$

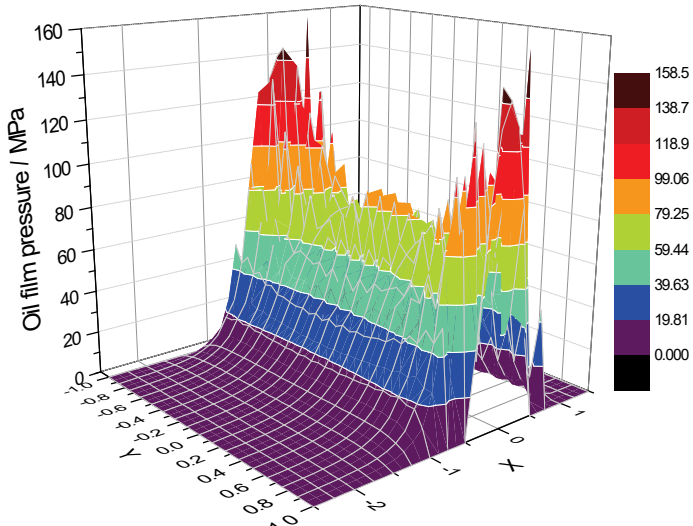

(d) $R a=0.1 h_{0}$

Figure 8 The three-dimensional oil film pressure

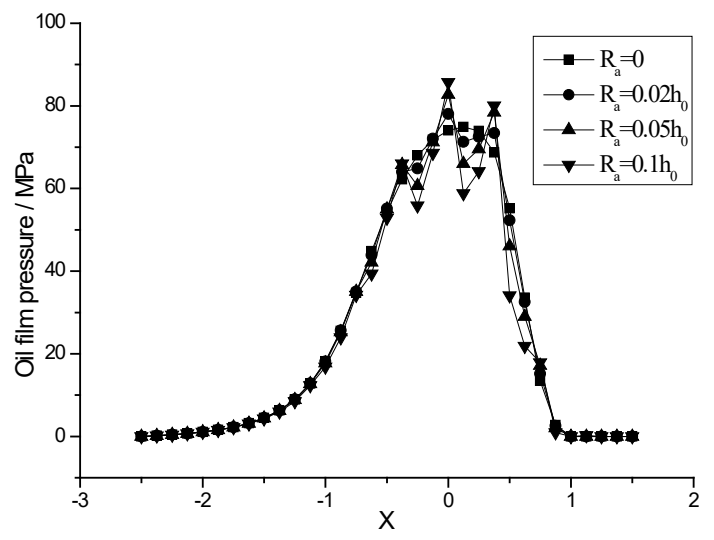

(a) $Y=0$

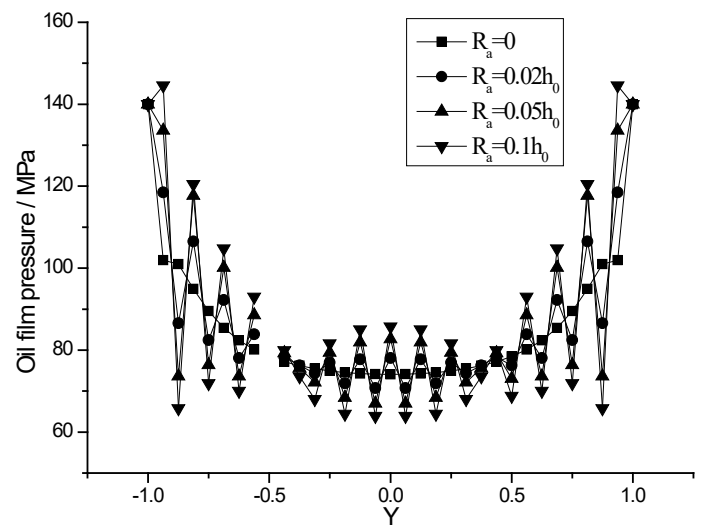

(b) $X=0$

Figure 9 The two-dimensional oil film pressure 


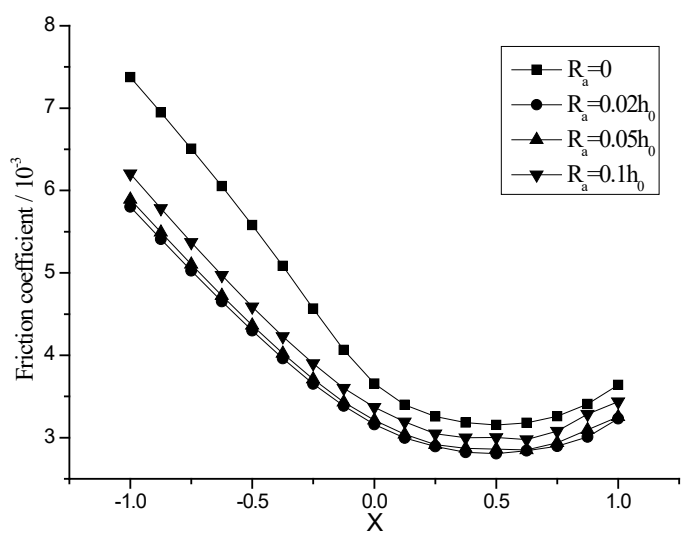

(a) $Y=0$

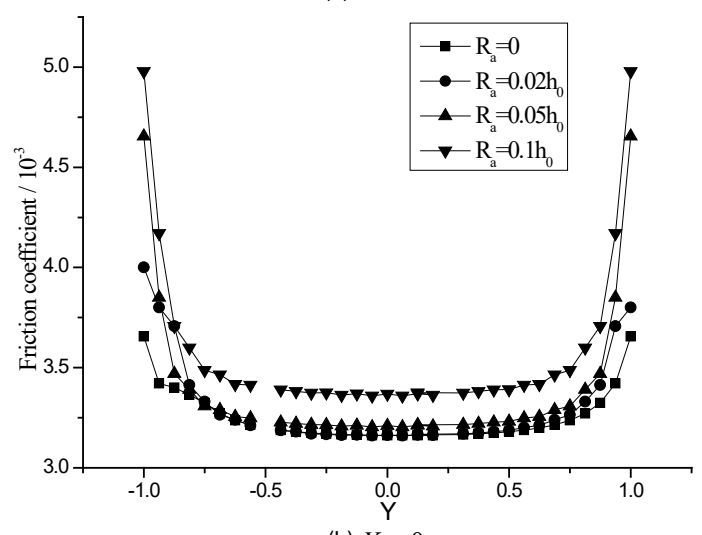

(b) $X=0$

Figure 10 The two-dimensional friction coefficient

It can be seen from Fig. 10 that with the increase of roughness amplitude, the friction coefficient decreases first and then increases in the suction direction. If the amplitude is in a certain range, the friction coefficient will decrease, and if the amplitude exceeds the certain range, the friction coefficient will increase greatly with the increase of the amplitude. The increase of surface roughness amplitude can decrease the friction coefficient to improve the friction conditions, but the unrestrained increase will affect the load distribution.

\subsection{The Effect of Surface Roughness Wavelength $l$}

In this part, the effect of the surface roughness wavelength will be analyzed. When the surface roughness amplitude is $0.08 h_{0}$ and the texture angle is $60^{\circ}$, the calculation was carried out with different surface roughness wavelengths of $l=+\infty, 0.2 b, 0.5 b$ and $0.8 b$. Fig. 11 and Fig. 13 show the three-dimensional distribution of oil film thickness and pressure with different surface roughness wavelengths, receptively. When $Y=0$ and $X=$ 0 , the two-dimensional oil film thickness, pressure and the friction coefficient are shown in Fig. 12, Fig. 14 and Fig. 15 , respectively. From the calculation results we know that the value of surface roughness wavelength has great influence on the EHL characteristics of cylindrical roller bearings.

It can be seen from Fig. 11 and Fig. 12, that with the increase of the surface roughness wavelength, the oil film thickness increases first and then decreases. In the reasonable range of wavelength, the increase of the roughness wavelength makes the film thickness fluctuate and the oil film thickness at the end of the bearing increase, which reduces the end effect and improves the lubrication condition of the contact surface. Thus, to a certain extent, the increase of roughness wavelength improves the lubrication condition of bearing surface.

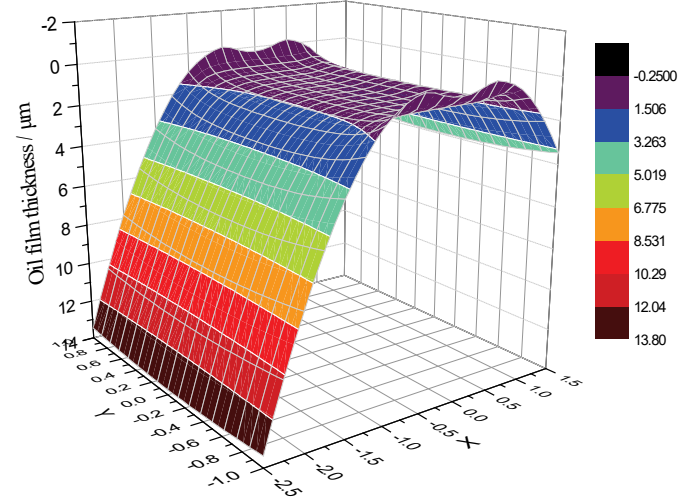

(a) $l=+\infty$

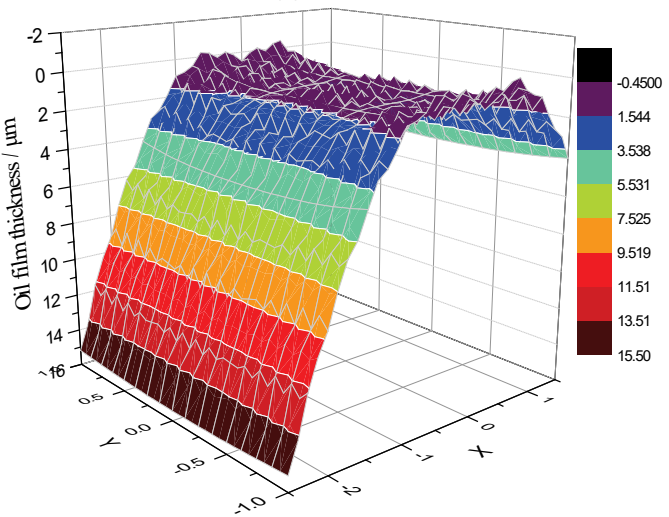

(b) $l=0.2 b$

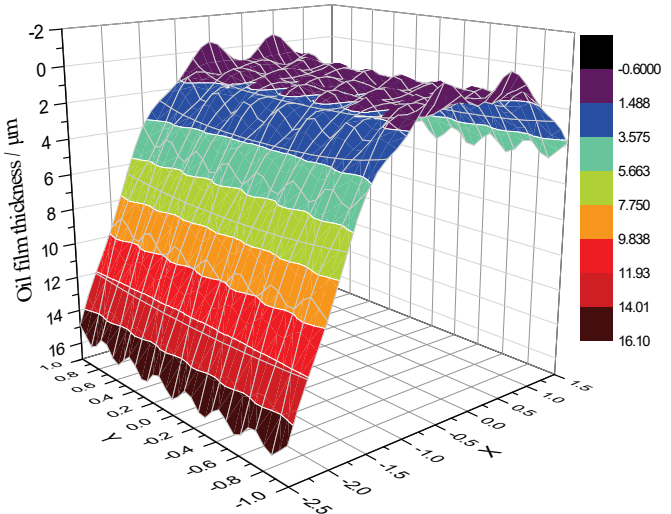

(c) $l=0.5 b$

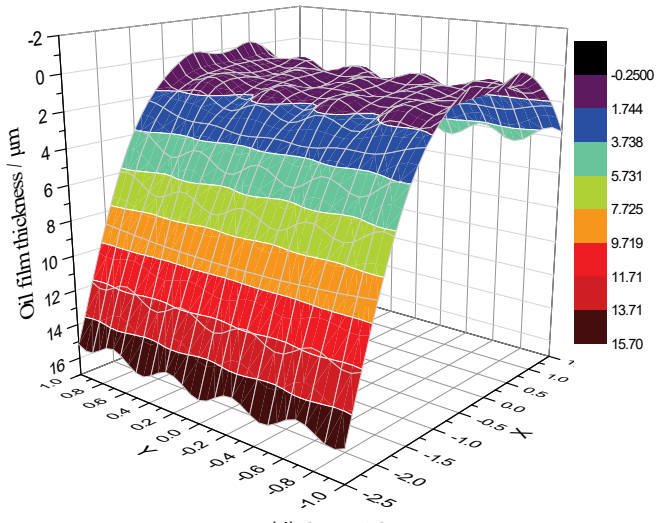

(d) $l=0.8 b$

Figure 11 The three-dimensional oil film thickness 


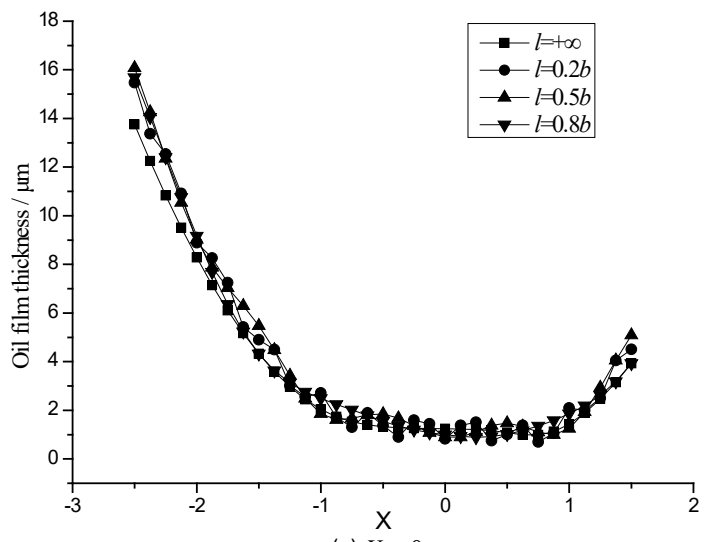

(a) $Y=0$

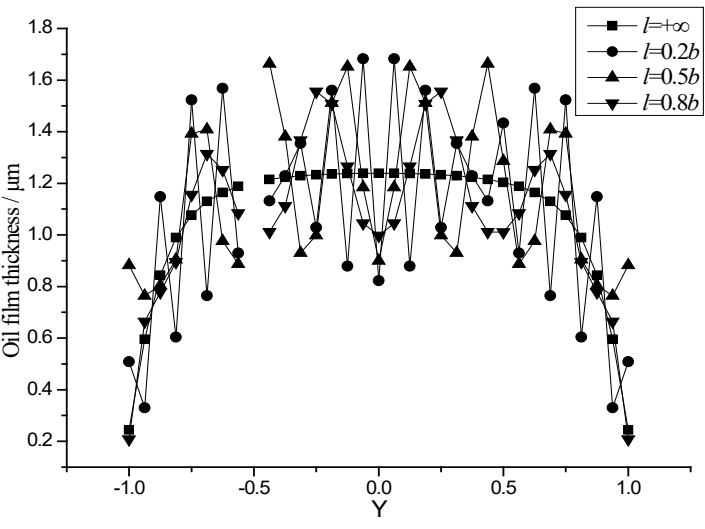

(b) $X=0$

Figure 12 The two-dimensional oil film thickness

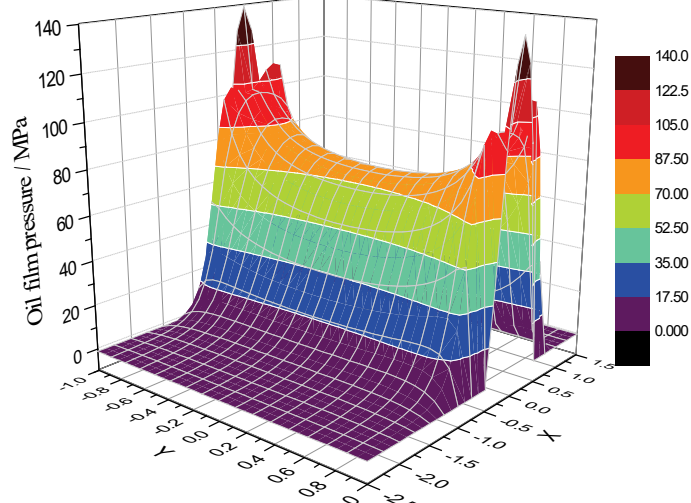

(a) $l=+\infty$

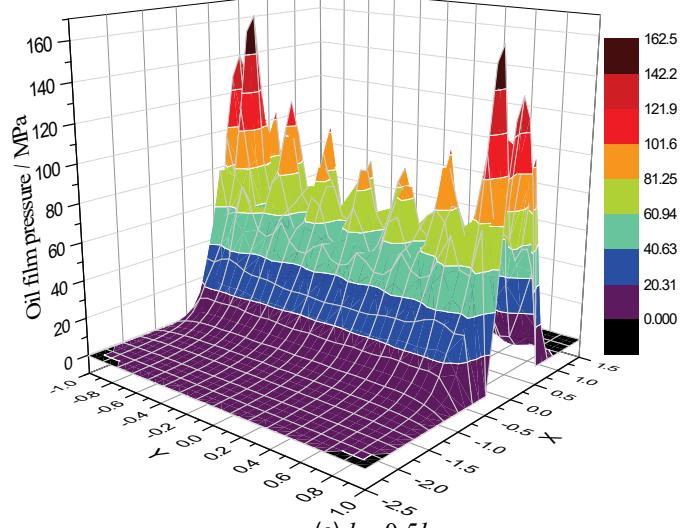

(c) $l=0.5 b$

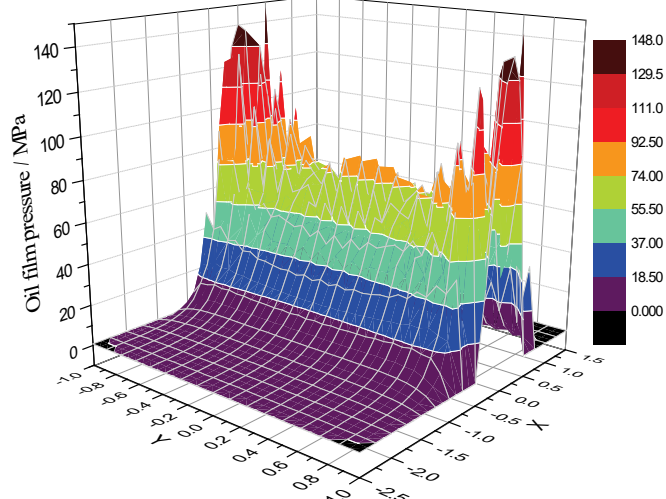

(b) $l=0.2 b$

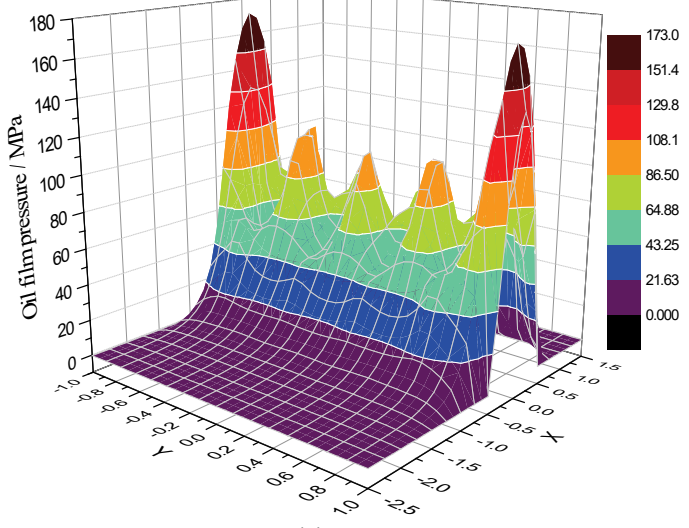

(d) $l=0.8 \mathrm{~b}$

Figure 13 The three-dimensional oil film pressure

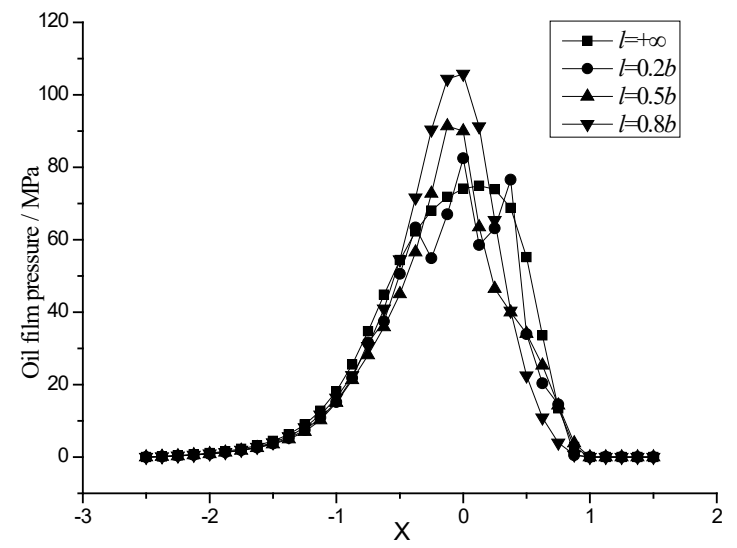

(a) $Y=0$

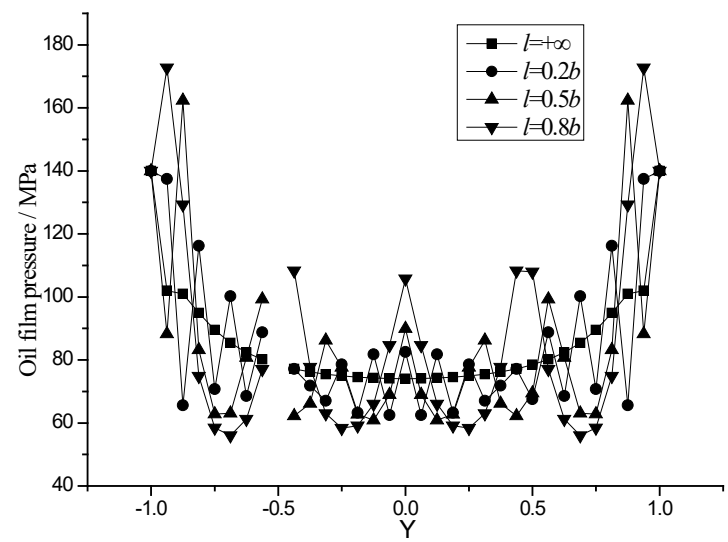

(b) $X=0$

Figure 14 The two-dimensional oil film pressure 
It can be seen from Fig. 13 and Fig. 14 that oil film pressure forms pressure peaks and valleys at the peaks and valleys of the roughness. In a certain range, the bearing capacity of oil film increases with the increase of wavelength. However, from Fig. 13(b) - 13(d), we know that the roughness wavelength cannot be increased much more, which will reduce the EHL performance and make the stress concentration at the end more obvious. The increase of roughness wavelength in a reasonable range is beneficial to the enhancement of EHL performance of cylindrical roller bearings.

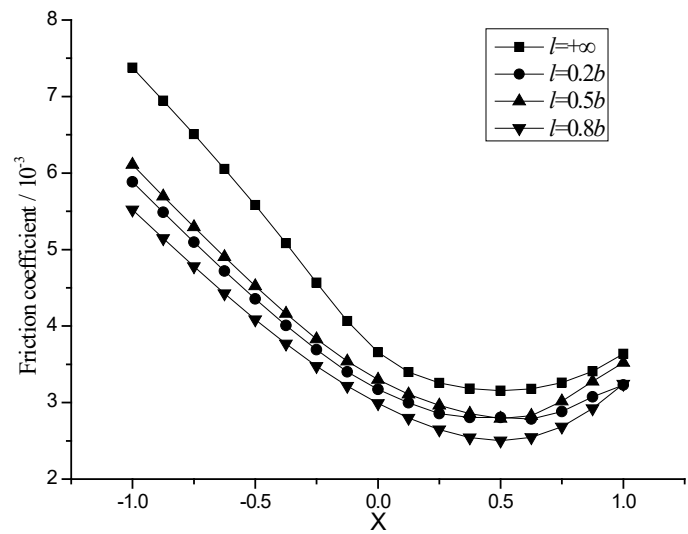

(a) $Y=0$

Figure 15 The two-dimensional friction coefficient

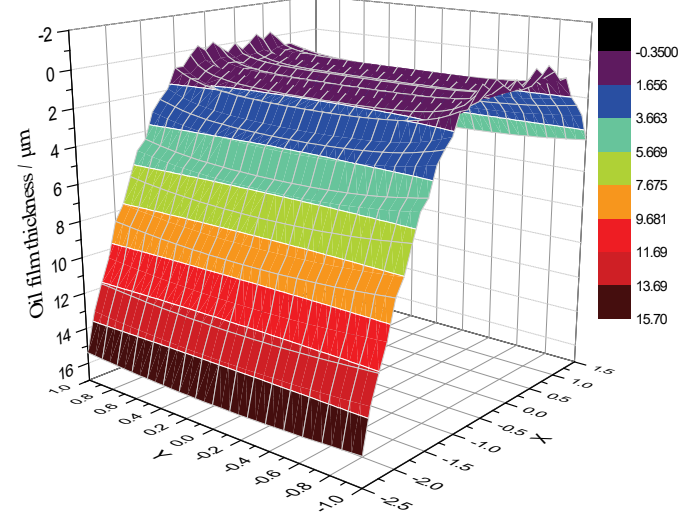

(a) $\beta=0^{\circ}$

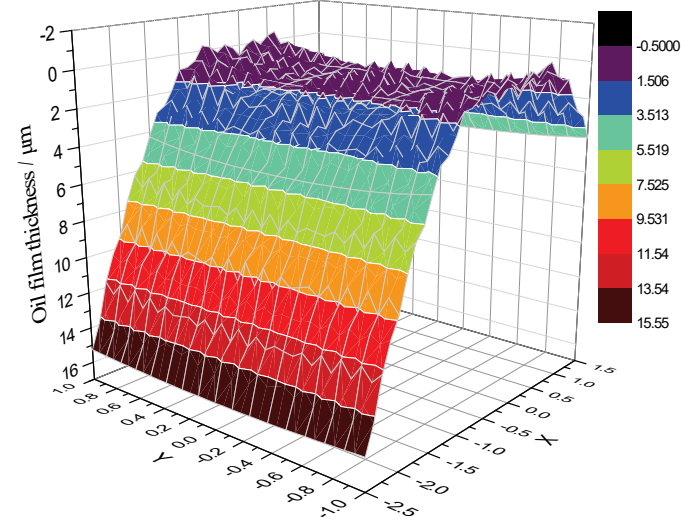

(c) $\beta=60^{\circ}$

Figure 16 The three-dimensional oil film thickness
It can be seen from Fig. 15 that with the increase of roughness wavelength, the friction coefficient increases first and then decreases in the suction direction, if the wavelength exceeds a certain range, the friction coefficient will increase significantly, and the same law to the friction coefficient in the busbar direction. It can be seen that the surface roughness wavelength affects the friction and wear of the roller contact pair, which increases the uncertainty of the bearing operation. Therefore, reasonable texture surface roughness is conducive to the long-term operation of the bearing.

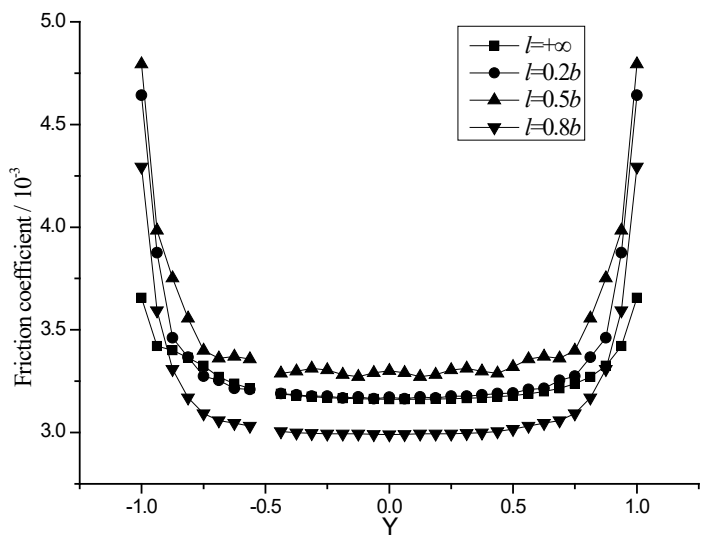

(b) $X=0$

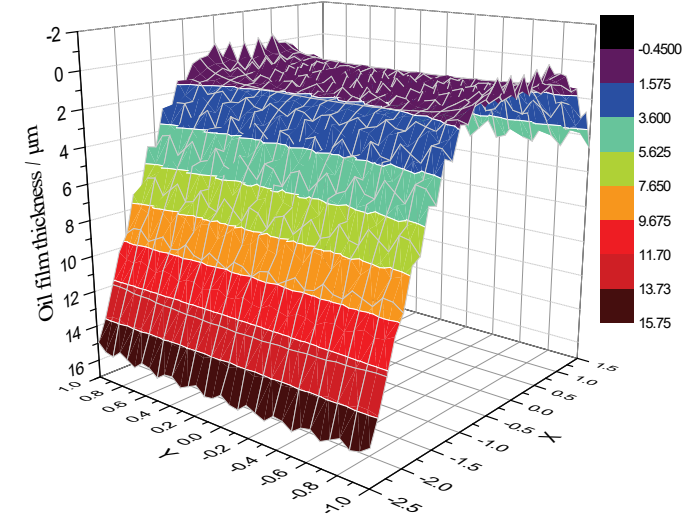

(b) $\beta=30^{\circ}$

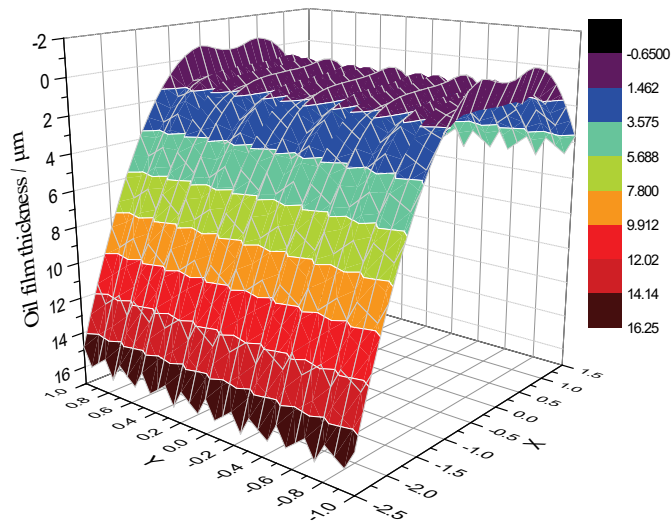

(d) $\beta=90^{\circ}$

\subsection{The Effect of Surface Roughness Texture Angle $\beta$}

The roughness texture angle is caused by the difference between the feed speed and the rotation speed of the workpiece when the surface is machined. In this part, the effect of the surface roughness texture angle will be analyzed. When the surface roughness amplitude is $0.05 h_{0}$ and the wavelength is $0.2 b$, the calculation is carried out with different surface roughness texture angles of $\beta=0^{\circ}$, 
$30^{\circ}, 60^{\circ}$ and $90^{\circ}$. Fig. 16 and Fig. 18 show the threedimensional distribution of oil film thickness and pressure with different surface roughness texture angles, respectively. When $Y=0$ and $X=0$, the two-dimensional oil film thickness, pressure and the friction coefficient are shown in Fig. 17, Fig. 19 and Fig. 20, respectively. From the calculation results we know that the value of surface roughness texture angle also has great influence on the EHL characteristics of cylindrical roller bearings.

Fig. 16(a) shows the oil film thickness distribution with texture angle $\beta=0^{\circ}$ (transverse texture), the three- dimensional oil film thickness along the suction direction distributes as cosine, and the oil film thickness decreases with the increase of roughness texture angle. Fig. 16(d) shows the oil film thickness distribution with texture angle $\beta=90^{\circ}$ (longitudinal texture), and the oil film thickness in the $X$ direction is the smallest, which is not conducive to the formation of the EHL oil film. When $\beta=0^{\circ}$, the end effect is the most obvious in the busbar direction, and the oil film thickness in the end region is the smallest. The end effect decreases with the increase of roughness texture angle.

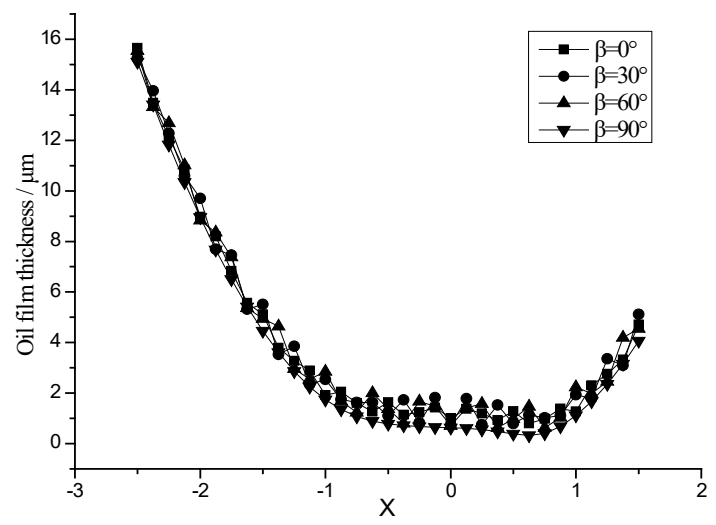

(a) $Y=0$

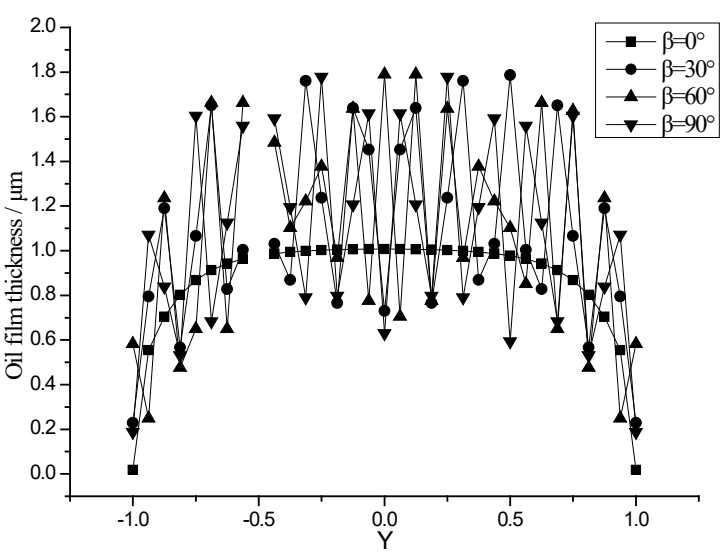

(b) $X=0$

Figure 17 The two-dimensional oil film thickness

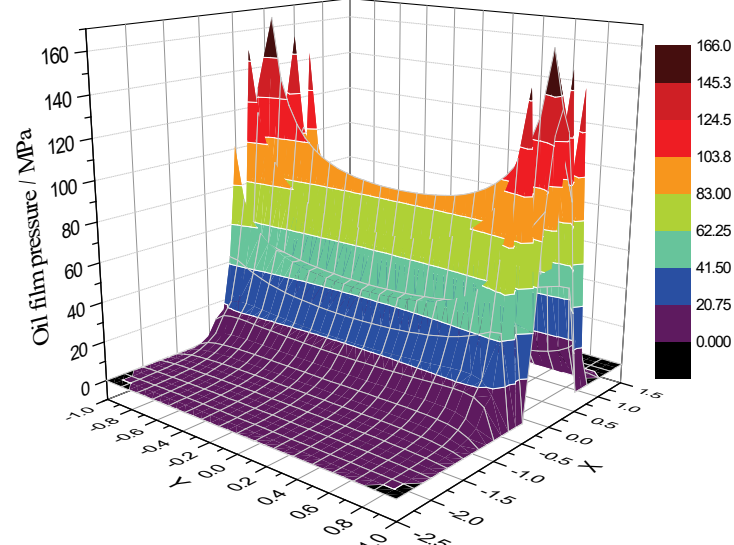

(a) $\beta=0^{\circ}$

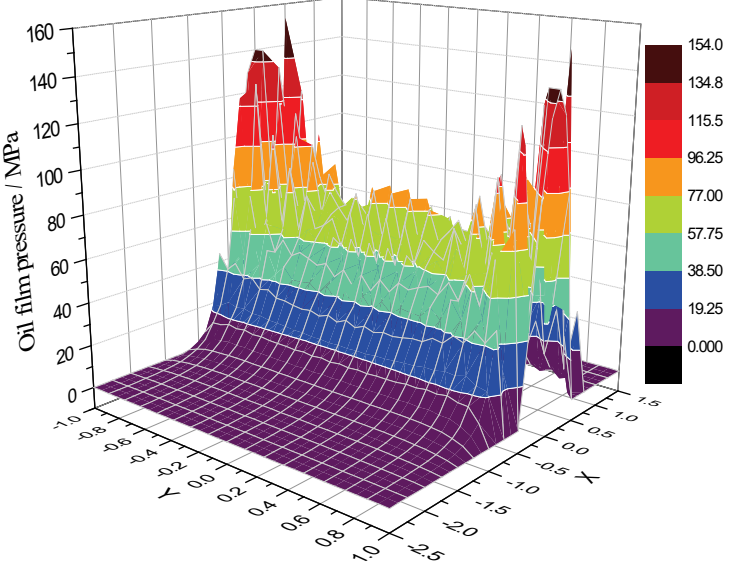

(c) $\beta=60^{\circ}$

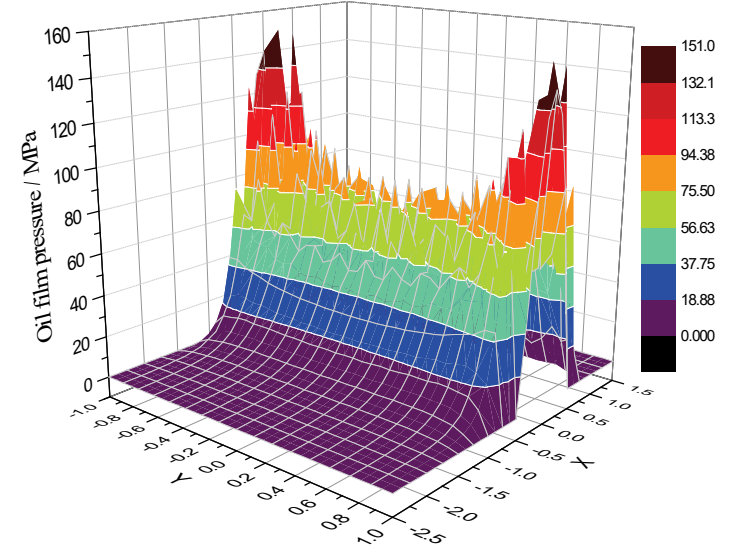

(b) $\beta=30^{\circ}$

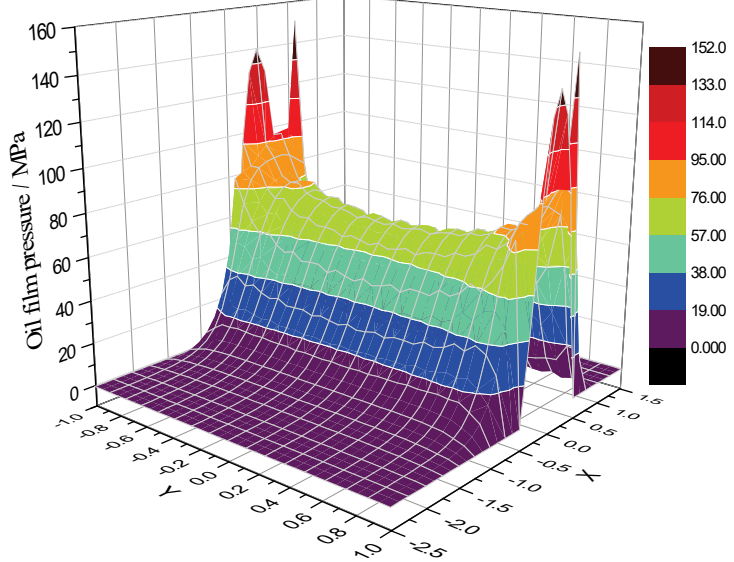

(d) $\beta=90^{\circ}$

Figure 18 The three-dimensional oil film pressure 


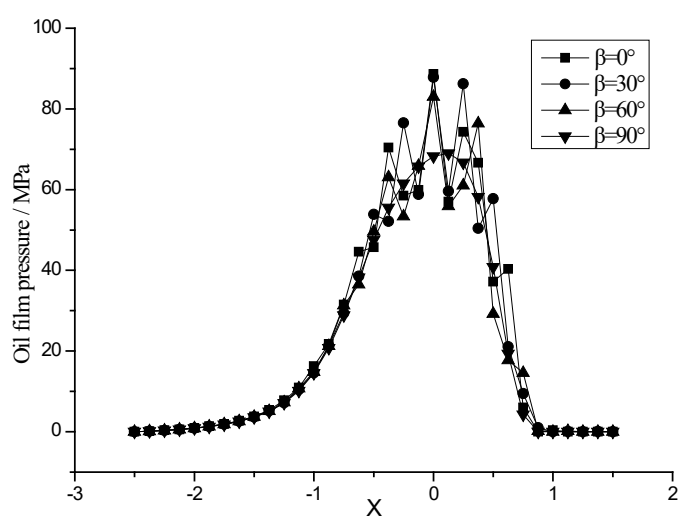

(a) $Y=0$

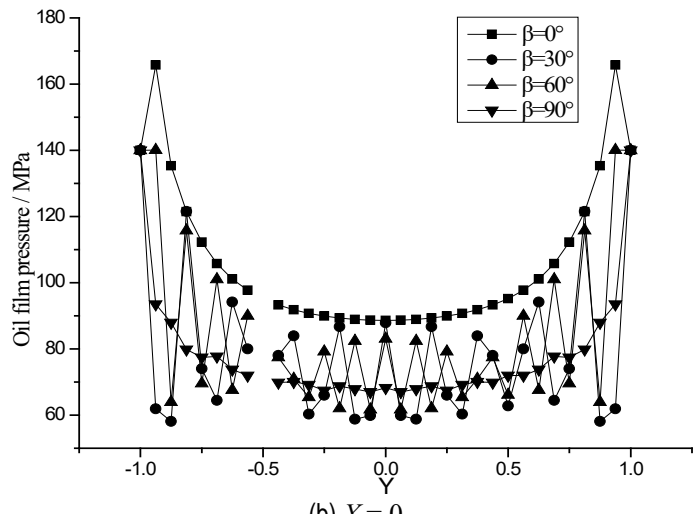

(b) $X=0$

Figure 19 The two-dimensional oil film pressure

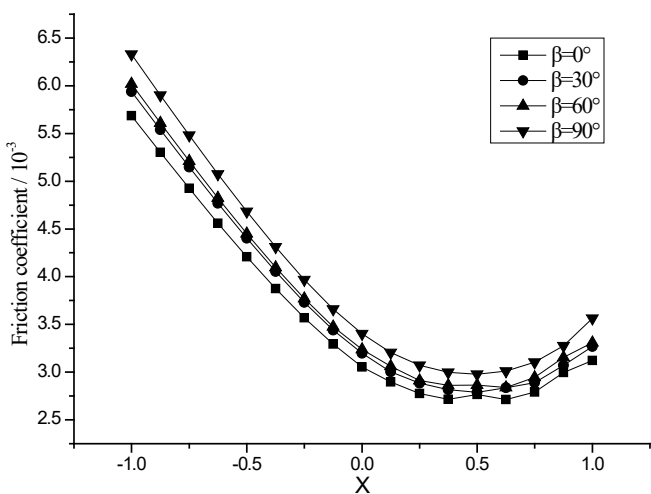

(a) $Y=0$

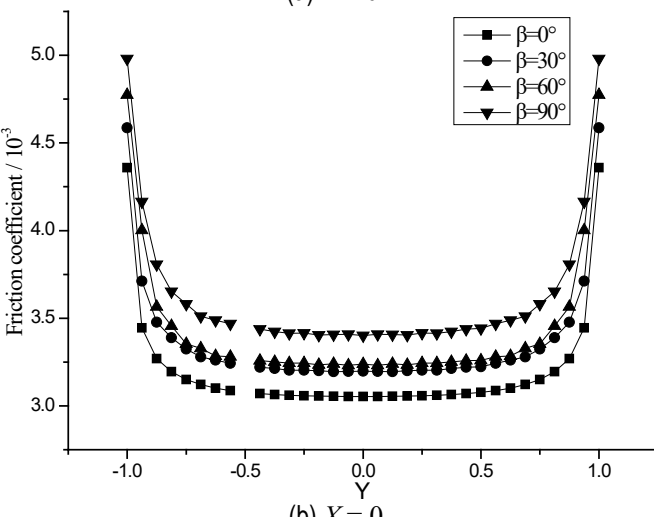

Figure 20 The two-dimensional friction coefficient

The effect of roughness texture angle on the oil film pressure distribution can be clearly seen in Fig. 18. When $\beta=0^{\circ}$, the oil film pressure peak increases, especially in the ends of the roller, the pressure value is twice as much as that in the middle region, which will decrease the reliability of the bearing. With the increase of texture angle, the bearing capacity of oil film decreases, and the end effect decreases also, which enhances the reliability of bearing. When the roughness texture angle is $\beta=90^{\circ}$, the oil film pressure is minimum because it cannot form an effective oil film, and the oil film pressure distribution is similar to the smooth condition.

It can be seen from Fig. 20, when $\beta=0^{\circ}$, the friction coefficient of the oil film is the smallest, because the transverse texture roughness can form a large number of lubrication oil in the peak and valley region, which can form an EHL oil film to separate the roller from the race effectively. When $\beta=90^{\circ}$, the effective oil film cannot be formed better, because of the leakage of lubrication oil in the busbar direction. Therefore, the film thickness is reduced, and the oil supply is insufficient, and there will be serious friction and wear problem on both the surfaces.

\section{CONCLUSION}

In this paper, an EHL model of cylindrical roller bearing with three dimensional cosine roughness based on finite length line contact theory is established, and the program of FDM is complied, by which the EHL performances of cylindrical roller bearing with different surface cosine roughness amplitude, wavelength and texture angle are calculated. According to the results of calculation, it is concluded that:

(1) With the increase of the surface roughness amplitude of the contact pair between the roller and the inner race, the oil film thickness increases along the suction direction and the busbar direction, the oil film pressure increases continuously and fluctuates sharply, and the friction coefficient decreases first and then increases in the suction direction. If the surface roughness amplitude is in a certain range, the increase of amplitude can improve the EHL performance of cylindrical roller bearing, but if the amplitude exceeds the certain value, it may bring harm to the operation of the bearing.

(2) With the increase of the surface roughness wavelength, the bearing capacity of oil film pressure will increase. However, the surface roughness wavelength is not the larger the better. The roughness wavelength cannot be increased much more, which will reduce the EHL performance and make the stress concentration at the end more obvious. The increase of roughness wavelength in a reasonable range is beneficial to the enhancement of EHL performance of the cylindrical roller bearing.

(3) With the increase of the surface roughness transverse texture, the oil film thickness and pressure decrease, and the friction coefficient increases. The transverse texture can form a good oil film shape, but enhance the end effect. Roughness longitudinal texture cannot form a good oil film and the oil film bearing capacity is low, but the end effect is the smallest. Therefore, selecting a reasonable processing technology to produce the surface with a certain texture angle can improve the bearing performance and prolong the service life.

\section{Acknowledgements}

This work was sponsored by the National Natural Science Foundation of China (51504157, 51404159 and 51875382) and Postdoctoral science foundation 
(2016M601288, 20172010 and 20152032). All these are gratefully appreciated.

\section{REFERENCES}

[1] Grubin, A. N. (1949). Fundamentals of the Hydrodynamic Theory of Lubrication of Heavily Loaded Cylindrical Surfaces. Central Scientific Institute for Technology and Mechanical Engineering, Moscow.

[2] Goglia, P. R., Cusano, C., \& Conry, T. F. (1984). The Effects of Surface Irregularities on the Elastohydrodynamic Lubrication of Sliding Line Contacts. Part II-Wavy Surfaces. Journal of Tribology, 106(1), 113. https://doi.org/10.1115/1.3260846

[3] Lin T. R. (1994). Steady state performance of finite hydrodynamic journal bearing with three-dimensional irregularities. Wear, 176(1), 95-102. https://doi.org/10.1016/0043-1648(94)90202-X

[4] Johns, P. M. \& Gohar, R. (1981). Roller Bearings under Radial and Eccentric Loads. Tribology International, 14, 131-136. https://doi.org/10.1016/0301-679X(81)90058-X

[5] Xu, W., Ma, J. J., \& Chen, X.Y. (1998). Elastohydrodynamic Lubrication of Finite Line Contacts. Part I: A Numerical Analysis of EHL for Finite Cylindrical Roller Contacts I. Tribology, 18(1), 39-44. https://doi.org/10.16078/j.tribology.1998.01.007

[6] Elsharkawy, A. A. \& Guedouar, L. H. (2002). The effects of surface irregularities on the performance characteristics of flexible finite journal bearings lubricated with couple stress fluids. Lubrication Science, 15(1), 51-72. https://doi.org/10.1002/ls.3010150105

[7] Liu, X. \& Yang, P. (2002). Analysis of the Thermal Elastohydrodynamic Lubrication of a Finite Line Contact. Tribology International, 35, 137-144. https://doi.org/10.1016/S0301-679X(01)00107-4

[8] Najjari, M. \& Guilbault, R. (2014). Edge contact effect on thermal elastohydrodynamic lubrication of finite contact lines. Tribology International, 71, 50-61. https://doi.org/10.1016/j.triboint.2013.11.005

[9] Liu, X. L. \& Yang, P. R. (2011). Influence of roller pairs temperature on lubricating behavior. Journal of Mechanical Engineering, 47(7), 123-127. https://doi.org/10.3901/JME.2011.07.123

[10] Huang, P. \& Zheng, J. (1996). Effect of roughness on lubrication of low elastic modulus in line contact. Journal of Tsinghua University (Sci\& Tech), 36(10), 50-55. https://doi.org/10.16511/j.cnki.qhdxxb.1996.10.010

[11] Niu, R. J. \& Huang, P. (2006). The Influences of Elasticplastic Deformation of Rough Surfaces on Elastohydrodynamic Lubrication for Line Contacts. Lubrication Engineering, 6, 20-23. https://doi.org/10.3969/j.issn.0254-0150.2006.06.006.

[12] Zhu, D., Wang, J. X., Ren, N., et al. (2012). Mixed elastohydrodynamic lubrication in finite roller contacts involving realistic geometry and surface roughness. ASME Journal of Tribology, 134(1), 97-104. https://doi.org/10.1115/1.4005952

[13] He, T., Wang, J. X., Wang, Z. J. et al. (2015). Simulation of plasto-elastohydrodynamic lubrication in line contacts of infinite and finite length. ASME Journal of Tribology, 137(4), 041505. https://doi.org/10.1115/1.4030690

[14] Lu, Z. Y., Lu, Y. J., Li, S., et al. (2017). Thermal Elastohydrodynamic Lubrication Analysis of Cylindrical Roller Bearing Considering Thermal Elastic Deformation and Surface Roughness. Journal of Mechanical Engineering, 54(13), 159-169. https://doi.org/10.3901/JME.2018.13.159

[15] Fu, H., Fu, Y. H., Ji, J. H., et al. (2018). Influence of short grooves on hydrodynamic lubrication of textured infinitely long sliders. Advances in Mechanical Engineering, 10(2), 1-
10. https://doi.org/10.1177/1687814018758907

[16] Liu, M. Y., Liu, H. J., Zhu, C. C. et al. (2015). Effects of rough surface topography on the characteristics of mixed lubrication in finite line contact. Tribology, 35(6), 690-698. https://doi.org/10.16078/j.tribology.2015.06.007

[17] Zapletal, T., Sperka, P., Krupka, I. et al. (2018). The effect of surface roughness on friction and film thickness in transition from EHL to mixed lubrication. Tribology International, 128, 356-364. https://doi.org/10.1016/j.triboint.2018.07.047

[18] Hultqvist, T., Shirzadegan, M., Vrcek, A. et al. (2018). Elastohydrodynamic lubrication for the finite line contact under transient loading conditions. Tribology International, 127, 489-499. https://doi.org/10.1016/j.triboint.2018.06.035

[19] Lu, Z. Y., Lv, Y. J., Zhang, Y. F. et al. (2018). Micro thermal elastohydrodynamic lubrication analysis of angular contact ball bearing considering thermal elastic deformation. Tribology, 38(3), 299-308. https://doi.org/10.16078/j.tribology.2018.03.007

[20] Huang, P. (2013). Numerical calculation methods of elastohydrodynamic lubrication. Tsinghua University Press, Beijing.

\section{Contact information:}

Xia YANG, Associate Professor

(Corresponding author)

Taiyuan University of Science and Technology,

School of Mechanical Engineering

Wanbolin district, Waliu street No. 66

Taiyuan City, Shanxi Province, China

Yachao LI, Postgraduate

Beijing Construction Engineering Group Shanxi Construction Co., Ltd. Jinyuan District Healthy South Street No. 1 Shanxi Sports Center,

Taiyuan City, Shanxi Province, China.

Guangming LIU, Professor

Taiyuan University of Science and Technology,

School of Mechanical Engineering

Wanbolin district, Waliu street No. 66

Taiyuan City, Shanxi Province, China

\section{Jianmei WANG, Professor}

Taiyuan University of Science and Technology,

School of Mechanical Engineering

Wanbolin district, Waliu street No. 66

Taiyuan City, Shanxi Province, China 